\title{
Early discharge of low birthweight infants*
}

\author{
FRANCINE LEFEBVRE, ANNIE VEILLEUX, AND HARRY BARD
}

\author{
Department of Pediatrics, University of Montreal, Neonatology Service, and Pediatric Research \\ Centre, Sainte-Justine's Hospital, Montreal, Canada
}

SUMMARY A study was conducted to see if the discharge weight of preterm infants born at $\leq 2000 \mathrm{~g}$ could safely be reduced. A study group (21 infants) was discharged 'early' at a mean weight of $2010 \mathrm{~g}$ (1890-2190) provided there were no medical problems, weight gain was adequate, temperature control in room air was stable, all feedings were by breast, and the mother was ready to have the baby home. A control group (17 infants) was discharged at a mean weight of $2261 \mathrm{~g}$ (2200-2400). The duration of time in hospital for the 'early' group was shortened by 11.6 days. At expected date of delivery the weight of infants in each group was similar $(3095 \pm 403$ compared with $3146 \pm 453 \mathrm{~g})$; length, head circumference, and haemoglobin concentration in each group were similar too. There was no morbidity or mortality in either group. Early discharge did not affect mothering confidence. This study shows that low birthweight infants can be discharged early (at $2000 \pm 100 \mathrm{~g}$ ) provided appropriate criteria are met, home conditions are adequate, and follow-up is available.

Several studies ${ }^{1-8}$ have shown there is little justification in waiting for a predetermined weight before discharging preterm newborn infants, but it is still the custom in many hospitals in Canada not to allow such infants to be discharged until they reach $2500 \mathrm{~g}$.

Early discharge allows increased contact between mother and infant which encourages mother-infant bonding. ${ }^{9}$ Other advantages of an earlier discharge would be that costs of the hospital would be lower, more beds and nursing time would be available for acutely ill infants, and there would be less danger of hospital-acquired infections.

\section{Methods}

Infants born at this hospital between October 1979 and June 1980 , weighing $2000 \mathrm{~g}$ or less at birth, whose parents lived in the Montreal metropolitan area were studied. These newborn infants were divided into two groups. Those born on odd days comprised the early discharge group and were discharged at less than $2200 \mathrm{~g}$ provided the following criteria were met: (1) they were clinically well and any medical problem was under control; (2) they had outgrown their birthweight and established satisfactory weight gain; (3) they had stable temperature control in room air (infants were taken out of

*Study presented at the 58th annual meeting of the Canadian Paediatric Society, Winnipeg, Manitoba, 26-30 June 1981. the incubator when they reached $1800 \mathrm{~g}$ ); (4) they were taking all their feedings by breast; (5) the mother was capable of caring for the infant at home (this information was obtained from the nurses in the hospital and from home visiting nurses). The infants born on even days comprised the control group and were discharged in accordance with the same criteria but when their weights were between 2200 and $2400 \mathrm{~g}$ (Figure).

In order to compare the effects of early discharge, the existing programme of the neonatal clinic was used: evaluation of the home environment by home visits (one visit before and one after discharge, and thereafter as required), record of medical problems (emergencies, outpatient visits, readmissions), as well as routine examinations (2- to 4-week intervals). The indexes of growth (weight, height, head circumference, and haemoglobin concentration), as well as the incidence of breast feeding were noted. These data were then compared for each group at the expected date of delivery.

Twenty-one infants in the early discharge group and 17 in the control group were studied. All were appropriate for gestational age preterm infants except for one small gestational age infant weighing $1890 \mathrm{~g}$ at 36 weeks in the early discharge group. The hospital's neonatal records of all the infants in the study were reviewed. Table 1 shows that the infants in the two groups were comparable for gender, birthweight, gestational age, neonatal illnessesnamely neonatal asphyxia, need for mechanical 
ventilation, respiratory distress syndrome, apnoeas and bradycardias, and exchange transfusion. There were more multiple pregnancies in the early discharge group than in the control group (7 compared with 3). There were 3 sets of twins in the early discharge group compared with one set in the control group. Mother's age, parity, and marital status were similar in both groups.

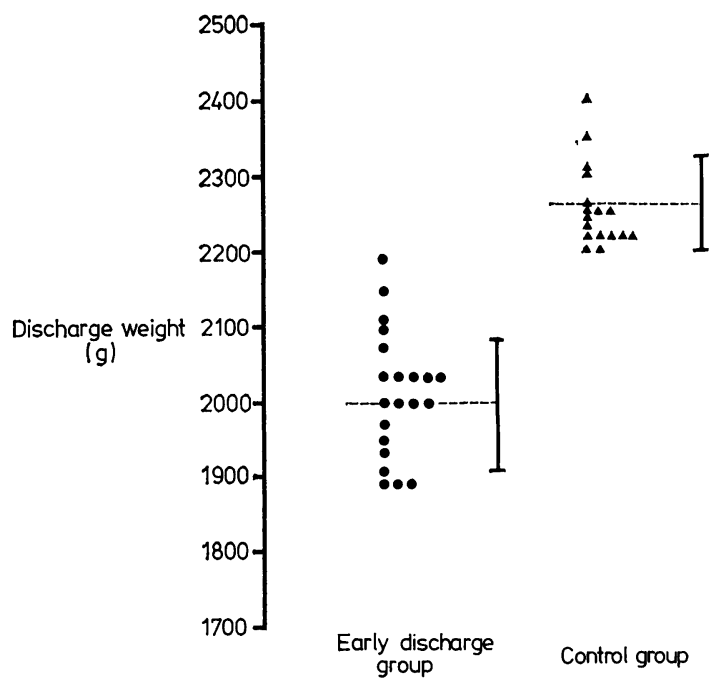

Figure Distribution of infants and mean and standard deviation of discharge weights for the 'early' discharge group compared with the controls.

Table 1 Perinatal data for the early and control groups

\begin{tabular}{|c|c|c|}
\hline & $\begin{array}{l}\text { Early } \\
(n=21)\end{array}$ & $\begin{array}{l}\text { Control } \\
(n=17)\end{array}$ \\
\hline Gender (male, female) & 10,11 & 8,9 \\
\hline Birthweight (g) (mean \pm SD) & $1655 \pm 214$ & $1533 \pm 293$ \\
\hline Range & $1000-1960$ & $900-1940$ \\
\hline Gestation (weeks) (mean $\pm S D)$ & $32 \cdot 1 \pm 2$ & $31 \cdot 2 \pm 2$ \\
\hline Range & $27-36$ & $28-34$ \\
\hline Twins or triplets & 10 & 4 \\
\hline \multicolumn{3}{|l|}{ Neonatal illnesses } \\
\hline Moderate neonatal asphyxia & 5 & 8 \\
\hline Severe neonatal asphyxia & 2 & 0 \\
\hline Mechanical ventilation (IPPV) & 4 & 3 \\
\hline Respiratory distress syndrome & 4 & 4 \\
\hline Apnoeas and bradycardias & 7 & 7 \\
\hline Exchange transfusion & 1 & 3 \\
\hline \multicolumn{3}{|l|}{ Mothers } \\
\hline Age (years) (mean \pm SD) & $\begin{array}{l}26 \cdot 1 \pm 3 \cdot 3 \\
(21-32)\end{array}$ & $\begin{array}{l}28 \cdot 3 \pm 5 \cdot 7 \\
(18-39)\end{array}$ \\
\hline $\begin{array}{l}\text { Primiparous : multiparous } \\
\text { Married : unmarried : unknown }\end{array}$ & $\begin{array}{l}10: 8 \\
17: 1: 0\end{array}$ & $\begin{aligned} & 9: 7 \\
& 13: 1: 2\end{aligned}$ \\
\hline \multicolumn{3}{|c|}{ Home visits } \\
\hline Good home & 15 & 12 \\
\hline Mediocre home & 2 & 3 \\
\hline No visit & 1 & 1 \\
\hline
\end{tabular}

No significant difference between the two groups.
Before discharge, neonatal visiting nurses visited each home to make sure that it was adequate. All infants were seen in the neonatal follow-up clinic or by a private paediatrician within a week of the expected date of the delivery. The results of these studies were compared for statistical analysis using the Student's $t$ test at the 2 P significance level.

\section{Results}

Data for the two groups of infants at birth, on discharge, and at their expected date of delivery are shown in Tables 1 and 2. Birthweights and gestational ages of each group were similar. The mean discharge weight for the early group was $2010 \pm 84 \mathrm{~g}$ (range 1890-2190), and 11 of the 21 infants in this group were sent home at $2000 \mathrm{~g}$ or less. The mean discharge weight for the control group was appreciably greater: $2261 \pm 59 \mathrm{~g}$ (range 2200-2400). Weight and head circumference were different in each group at discharge. As shown (Table 2) the duration of time in hospital was shorter by a mean of 11.6 days for the infants discharged early. When all the infants in this study had reached their expected date of confinement there was no difference between the two groups. The early group reached a weight of $3095 \pm 403 \mathrm{~g}$ (range 2440-3190) while the controls reached $3146 \pm 453 \mathrm{~g}$ (range 2440-4195). The measurement of head circumference and length was also similar. The mean weight attained in the two groups corresponds to about the 25 th centile, the mean length to the 20th centile, and the mean head circumference to the 50th centile on the Montreal intrauterine growth chart. ${ }^{10}$ Neither was there any difference in mean haemoglobin concentration between the two groups $(9.6 \mathrm{~g} / \mathrm{dl}$ in the early group and $10.5 \mathrm{~g} / \mathrm{dl}$ in the controls).

During the period between discharge and the expected date of delivery, 4 of the infants from the early group and 2 controls were brought to the hospital's emergency room. Two infants from the early group were diagnosed as having upper respiratory tract infection for which one was admitted for observation. This infant did not require any treatment and the admission was regarded as unnecessary. Two control infants and 2 early discharge infants were also seen for benign gastrointestinal symptoms or trivial complaint.

At the time of discharge, 6 of the early group infants and 7 controls were partially fed by their mothers' expressed breast milk. At the expected date of confinement, only 2 of the early group infants were still being breast fed and the breast feeding continued until 2 and 3 months after the expected date of delivery. There were 3 control infants on mother's milk at the expected date of 
Table 2 Growth data on discharge and at expected date of delivery, and duration of time in hospital

\begin{tabular}{|c|c|c|c|}
\hline & Early group & Control group & $P$ \\
\hline $\begin{array}{l}\text { Discharge } \\
\text { Weight (g) } \\
\text { Range }\end{array}$ & $\begin{array}{l}2010 \pm 84 \\
1890-2190 \\
(n=21)\end{array}$ & $\begin{array}{l}2261 \pm 59 \\
2200-2400 \\
(n=17)\end{array}$ & $<0.001$ \\
\hline $\begin{array}{l}\text { Length (cm) } \\
\text { Range }\end{array}$ & $\begin{array}{l}45 \cdot 3 \pm 0 \cdot 8 \\
44-47 \\
(n=9)\end{array}$ & $\begin{array}{l}46 \cdot 2 \pm 1 \cdot 2 \\
45-49 \\
(n=13)\end{array}$ & NS \\
\hline $\begin{array}{l}\text { Head } \\
\text { circumference (cm) } \\
\text { Range }\end{array}$ & $\begin{array}{l}31 \cdot 8 \pm 0 \cdot 6 \\
30 \cdot 5-32 \cdot 5 \\
(n=17)\end{array}$ & $\begin{array}{l}32 \cdot 7 \pm 1 \cdot 0 \\
31 \cdot 5-34 \cdot 5 \\
(n=15)\end{array}$ & $<0.01$ \\
\hline $\begin{array}{l}\text { Expected date of deliver } \\
\text { Weight (g) } \\
\text { Range }\end{array}$ & $\begin{array}{l}\text { y } \\
2495 \pm 403 \\
2440-3910 \\
(n=21)\end{array}$ & $\begin{array}{l}3146 \pm 453 \\
2440-4195 \\
(n=17)\end{array}$ & NS \\
\hline $\begin{array}{l}\text { Length }(\mathrm{cm}) \\
\text { Range }\end{array}$ & $\begin{array}{l}48 \cdot 2 \pm 1 \cdot 7 \\
44 \cdot 4-50 \cdot 7 \\
(n=21)\end{array}$ & $\begin{array}{l}49 \cdot 4 \pm 2 \cdot 2 \\
47 \cdot 6-54 \cdot 6 \\
(n=16)\end{array}$ & NS \\
\hline $\begin{array}{l}\text { Head } \\
\text { circumference }(\mathrm{cm}) \\
\text { Range }\end{array}$ & $\begin{array}{l}35 \cdot 2 \pm 1 \cdot 0 \\
33 \cdot 5-37 \\
(n=20)\end{array}$ & $\begin{array}{l}35 \cdot 4 \pm 1 \cdot 0 \\
33-37 \\
(n=16)\end{array}$ & NS \\
\hline $\begin{array}{l}\text { Haemoglobin }(\mathrm{g} / \mathrm{dl}) \\
\text { Range }\end{array}$ & $\begin{array}{l}9 \cdot 6 \pm 1 \cdot 0 \\
8 \cdot 0-12 \cdot 2 \\
(n=20)\end{array}$ & $\begin{array}{l}10 \cdot 5 \pm 1 \cdot 6 \\
8 \cdot 9-14 \cdot 6 \\
(n=14)\end{array}$ & NS \\
\hline $\begin{array}{l}\text { Duration of time in } \\
\text { hospital (days) } \\
\text { Range }\end{array}$ & $\begin{array}{l}26 \cdot 3 \pm 15 \cdot 2 \\
8-74 \\
(n=21)\end{array}$ & $\begin{array}{l}37 \cdot 9 \pm 14 \cdot 5 \\
15-61 \\
(n=17)\end{array}$ & $<0.025$ \\
\hline
\end{tabular}

Mean \pm SD. NS = non significant.

delivery, 2 of whom were still being breast fed 2 and 7 months later.

\section{Discussion}

This study shows that it is not necessary to keep clinically well preterm newborn infants in hospital until they reach a weight of $2500 \mathrm{~g}$. It also shows that the length of stay in hospital can be shorter if infants are discharged at $2000 \pm 100 \mathrm{~g}$ under adequate conditions. This report shows that there were no adverse effects of weight gain or other measures of growth. No infant died and there was no significant medical problem; only one infant was admitted to hospital and this was unnecessary. Unfortunately, because there were few infants in the study there was no means of demonstrating an enhancement of breast feeding. Early discharge created no problem in cases of preterm multiple births. A lack of mothering confidence could not be seen as there were no differences in the numbers of visits to the emergency clinic.

The results of this project show that provided home visits are made by nurses, early discharge can be encouraged. This should reduce the costs of intermediate care in neonatal nurseries and allow more staffing for infants who require intensive care. Perhaps early discharge of preterm newborn infants will help mother-infant bonding.

This study has confirmed what has been reported elsewhere. ${ }^{1-8}$ The duration of time in hospital was shortened by 11.6 days in our unit by discharging preterm newborn infants earlier. Neonatal units which continue to wait for a predetermined weight of $2500 \mathrm{~g}$ before discharge are unnecessarily prolonging time in hospital by at least 3 weeks.

\section{Conclusion}

This study demonstrates that discharge to an adequate home of low birthweight infants at $2000 \pm$ $100 \mathrm{~g}$ is safe, provided appropriate criteria are met and adequate follow-up is available.

We thank Miss Sylvie Collet; the staff of the neonatal clinic (Miss Renée-Berthe Oligny, Sister Simone Desjardins, and Mrs Elaine Rahbe) for assistance; Mrs Nicole Nérette for secretarial help.

\section{References}

1 Berg R B, Salisbury A J, Kahan R. 'Early' discharge of low-birth-weight infants. JAMA 1969; 210: 1892-6.

2 Berg R B, Salisbury A J. Discharging infants of low birth weight. Reconsideration of current practice. Am J Dis Child 1971; 122: 414-7.

3 Bauer C H, Tinklepaugh W. Low birth weight babies in the hospital. A survey of recent changes in their care, with special emphasis on early discharge. Clin Pediatr (Phila) 1971; 10: 467-9.

4 Dillard R G, Korones S B. Lower discharge weight and shortened nursery stay for the low birth weight infants. N Engl J Med 1973; 288: 131-3.

5 Singer B, Wolfsdorf J. Early discharge of infants of low birth weight: a prospective study. Br Med J 1975; i: 362-4.

- Singh M. Early discharge of low-birth-weight babies. Trop Geogr Med 1979; 31 : 565-9.

7 Lowry M F, Jones M R, Shanahan M D. Letter: Discharge of small babies from hospital. Arch Dis Child $1978 ; 53$ : 522-8.

8 Davies D P, Haxby V, Herbert S, McNeish A S. When should pre-term babies be sent home from neonatal units? Lancet 1979 ; i: 914-5.

9 Klaus M H, Kennell J H. Maternal infant bonding. St Louis: Mosby, 1976.

10 Usher R, McLean F. Intrauterine growth of liveborn Caucasian infants at sea level: standards obtained in 7 dimensions of infants born between 25 and 44 weeks of gestation. J Pediatr 1969; 74: 901-10.

Correspondence to Dr Francine Lefebvre, Hôpital Sainte-Justine, 3175 Chemin Sainte-Catherine, Montreal, Quebec H3T 1C5, Canada.

\section{Received 1 March 1982}

